\title{
BIOLOGIA DO JUNDIÁ Rhamdia quelen (TELEOSTEI, PIMELODIDAE)
}

\author{
BIOLOGY OF Rhamdia quelen (TELEOSTEI, PIMELODIDAE)
}

\section{Levy de Carvalho Gomes $^{1}$ Jaqueline Ineu Golombieski ${ }^{2}$ Adriana Regina Chippari Gomes ${ }^{1}$ Bernardo Baldisserotto ${ }^{3}$}

\section{- REVISÃO BIBLIOGRÁFICA -}

\section{RESUMO}

O jundiá, Rhamdia quelen, é encontrado desde o centro da Argentina até o sul do México, e seu cultivo está aumentando no sul do Brasil. Portanto, o objetivo desta revisão é apresentar os dados existentes até o momento sobre a biologia dessa espécie. R. quelen pode atingir $50 \mathrm{~cm}$ de comprimento e $3 \mathrm{~kg}$ de peso, possui hábito noturno e habita locais calmos e profundos

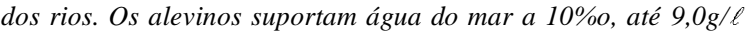
de sal comum e pH na faixa de 4,0 a 8,5, com melhor crescimento das larvas na faixa de $\mathrm{pH}$ de 8,0 a 8,5. É uma espécie euritérmica. Esse peixe é omnívoro, com tendência piscívora. A maturidade sexual é atingida no primeiro ano de vida. É uma espécie ovulípara e, na natureza, os cardumes desovam em locais com água limpa, calma e de fundo pedregoso. Não apresenta cuidado parental. Possui dois picos reprodutivos por ano (um no verão $e$ outro na primavera) e desova múltipla. A indução da desova apresentou bons resultados com gonadotrofina coriônica humana (HCG) ou extrato hipofisário. O desenvolvimento embrionário de $\boldsymbol{R}$. quelen é rápido e se dá entre 3 a 5 dias. $O$ melhor alimento artificial para larvas de $\boldsymbol{R}$. quelen é baseado em lecitina de soja fígado bovino e levedura. Várias bactérias patogênicas e trematódeos digenéticos já foram identificados em $\boldsymbol{R}$. quelen. Para um melhor aproveitamento dessa espécie na piscicultura, são necessários mais estudos relacionados ao efeito de parâmetros físicoquímicos da água, alimentação artificial e crescimento em cativeiro.

Palavras-chave: jundiá, Rhamdia quelen, piscicultura, reprodução.

\section{SUMMARY}

The jundiá, Rhamdia quelen, occurs from Southern Mexico to Central Argentina, and the husbandry of this species is spreading in Southern Brazil. Consequently, the aim of this review is to present the available data of the biology of this species. $\boldsymbol{R}$. quelen can reach $50 \mathrm{~cm}$ of length and $3 \mathrm{~kg}$ of weight, presents a nocturnal habit and lives in placid and deep waters of the rivers. Fingerlings support $10 \%$ seawater, up to $9 \mathrm{~g} / \ell$ table salt and $4.0-8.5 \mathrm{pH}$ range, with best growth at $8.0-8.5 \mathrm{pH}$ range. It is an eurytermal species. This fish is omnivorous, but prefers fish. The sexual maturity is reached in the first year of life, and it is ovuliparous and in the natural environment the schools spawn in clean and calm waters with rocky bottom. There is no parental care. This species shows two reproductive peaks/year (spring and summer) and multiple spawning. The induced spawning had good results with human chorionic gonadotrofin (HCG) or pituitary extract. The embriological development of $\boldsymbol{R}$. quelen is fast, and the larval development occurs in three to five days. The best feeding ration to the larvae of $\boldsymbol{R}$. quelen is based on soybean lecithin, cattle liver and yeast. Several pathogenic bacteria and digenetic trematoda were identified in $\boldsymbol{R}$. quelen. To improve the use of this species in fish culture, additional studies about physico-chemical parameters of the water, feeding rations and growth in captivity are essential.

Key words: jundiá, Rhamdia quelen, fish culture, reproduction

\section{INTRODUÇÃO}

O cultivo de Rhamdia quelen (jundiá) está aumentando no sul do Brasil, mas ainda está muito abaixo de suas possibilidades, pois vários parâmetros biológicos sobre a espécie estão faltando ou dispersos na literatura. Portanto, o objetivo deste trabalho é revisar os dados existentes sobre a biologia de $\boldsymbol{R}$. quelen e indicar futuros estudos que possam auxiliar no cultivo dessa espécie.

\footnotetext{
${ }^{1}$ Biólogo, Mestre em Zootecnia pela Universidade Federal de Santa Maria (UFSM).

${ }^{2}$ Bióloga, graduada em Ciências Biológicas pela (UFSM).

${ }^{3}$ Oceanólogo, Doutor, Professor Adjunto, Departamento de Fisiologia, UFSM, 97105.900 - Santa Maria - RS. Autor para correspondên-
} cia. E-mail: bernardo@ccs.ufsm.br. 
A espécie em estudo tem distribuição neotropical, do sudeste do México ao norte, e centro da Argentina ao sul (SILFVERGRIP, 1996). A sistemática do gênero Rhamdia é confusa desde que foi descrita. Recentemente, SILFVERGRIP (1996) realizou uma ampla revisão taxonômica do gênero, baseada em caracteres da morfologia interna, e concluiu que o gênero Rhamdia é formado de apenas 11 espécies dentre 100 anteriormente descritas. Segundo o mesmo autor, Rhamdia quelen pertence à seguinte divisão taxonômica: Classe: Osteichthyes, Série: Teleostei, Ordem: Siluriformes, Família: Pimelodidae, Gênero: Rhamdia, Espécie: Rhamdia quelen.

Além disso, SILFVERGRIP (1996) considera que Rhamdia quelen apresenta 49 sinonímias: Silurus quadrimaculatus, Pimelodus Quelen, Pimelodus sebae, Pimelodus nandia, Heterobranchus sextentaculatus, Pimelodus sapo, Pimelodus hilarii, Pimelodus pentlandii, Pimelodus Stegelichii, Pimelodus Sellonis, Pimelodus Deppei, Pimelodus musculus, Pimelodus sapipoca, Pimelenotus Vilsoni, Pimelodus cinerascens, Pimelodus guatemalensis, Pimelodus wuchereri, Pimelodus godmanni, Pimelodus micropterus, Pimelodus (Rhamdia) Baronis Mülleri, Pimelodus wagneri, Rhamdia bransfordii, Pimelodus (Rhamdia) Parabybae, Pimelodus (Rhamdia) Queleni cuprea, Pimelodus (Rhamdia) Cuyabae, Rhamdia oaxacae, Rhamdia depressa, Rhamdia gilli, Pimelodus Boucardi, Rhamdia beteracantha, Rhamdia barbata, Rhamdia nasuta, Rhamdia branneri, Rhamdia branneri voulezi, Rhamdia mounseyi, Rhamdia riojae, Rhamdia microps, Rhamdia pubescens, Silurus rivularis, Rhamdia micayi, CaecoRhamdia urichi, Rhamdia guatemalensis muriei, Rhamdia guatemalensis decolor, Rhamdia guatemalensis stygaaea, Rhamdia saijaensis, Rhamdia sebae Martyi, Rhamdia lehmanni. Nomes vulgares: Brasil: jundiá, jundiá-tinga, jandiá, jandiá-tinga, mandi e sapipoca. Argentina: bagre, bagre negro, bagre sapo e bagre sulamericano.

A coloração do jundiá varia de marromavermelhado claro a cinza ardósia. A pigmentação da parte inferior da cabeça é variável. Os barbilhões têm crescimento alométrico negativo e esta relação é provavelmente aumentada devido à grande possibilidade de dano dos barbilhões em exemplares grandes (SILFVERGRIP, 1996). Segundo o mesmo autor, $R$. quelen pode ser diferenciado das outras espécies de Rhamdia através das seguintes características: espinho da nadadeira peitoral serrilhado em ambos os lados; nadadeira caudal com lóbulos desiguais; membrana interradial menor do que $2 / 3$ do comprimento do raio do lobo superior da nadadeira caudal/ lobo inferior da nadadeira caudal; com ou sem poros sensoriais múltiplos na cabeça; véu da narina posterior aberta postero-lateralmente, barbilhões maxilares no mínimo $28,8 \%$ do comprimento padrão; arcos branquiais de 5 a 16; vértebras pós Weberianas de 36 a 44; olhos de tamanho médio, com ou sem padrão de manchas; com ou sem uma marca tipo selim escuro na nuca. O mesmo autor também faz uma descrição extensiva da osteologia dessa espécie, a qual não será repetida aqui.

$\boldsymbol{R}$. quelen vive em lagos e poços fundos dos rios, preferindo os ambientes de águas mais calmas com fundo de areia e lama, junto às margens e vegetação. Escondem-se entre pedras e troncos apodrecidos, de onde saem à noite, à procura de alimento (GUEDES, 1980). Em experimentos com larvas e alevinos dessa espécie em cativeiro, observou-se uma acentuada aversão à luz e busca de locais escuros (PIAIA et al., 1999).

Alevinos de $\boldsymbol{R}$. quelen suportam a transferência de água de $0 \%$ a $10 \%$ o (água do mar), o que indica que essa espécie é estenoalina, e suporta até $9,0 \mathrm{~g} / \ell$ de sal comum $(\mathrm{NaCl})$ por $96 \mathrm{~h}$, de modo que o tratamento de doenças com sal comum pode ser utilizado nesta espécie sem problemas (MARCHIORO, 1997). Experimentos de MARCHIORO (1997) demonstraram que os alevinos também suportam uma variação de $\mathrm{pH}$ na faixa de 4,0 a 8,5 (dureza de 30,0mg/ $\ell \mathrm{CaCO}_{3}$ ), mas estudos adicionais realizados pelos autores em laboratório (observações não publicadas) indicam que a tolerância dessa espécie ao $\mathrm{pH}$ alcalino pode ser maior (até pH 9,5). A exposição de alevinos de $\boldsymbol{R}$. quelen a águas ácidas ou alcalinas provoca uma redução dos níveis corporais de $\mathrm{Na}^{+}$e $\mathrm{K}^{+}$, como já relatado para outros teleósteos de água doce (MARCHIORO, 1997). O melhor crescimento das larvas dessa espécie foi observado na faixa de $\mathrm{pH}$ de 8,0 a 8,5 (LOPES, 1998). Os alevinos também suportam níveis de dureza de até pelo menos $600 \mathrm{mg} / \ell$ de $\mathrm{CaCO}_{3}$, por 96h, sem mortalidade (TOWNSEND et al., 1997).

Essa espécie pode ser considerada euritérmica, pois os alevinos aclimatados a $31^{\circ} \mathrm{C}$ suportam temperaturas de 15 a $34^{\circ} \mathrm{C}$. A aclimatação a temperaturas mais baixas proporciona uma maior tolerância à redução de temperatura, mas o limite superior de tolerância praticamente não se altera (CHIPPARI GOMES, 1998).

O crescimento de $\boldsymbol{R}$. quelen aumenta com o incremento da temperatura. Esse crescimento é bastante pronunciado nos primeiros anos de vida. A taxa de crescimento dos machos é maior do que a 
das fêmeas até o terceiro ou quarto ano de vida, quando a situação se inverte, pois estas passam a crescer mais rapidamente. $\mathrm{O}$ comprimento assintótico calculado das fêmeas é de aproximadamente $66,5 \mathrm{~cm}$ e dos machos de $52,0 \mathrm{~cm}$. Conseqüentemente, as fêmeas apresentam maior comprimento e idade que os machos, sendo que o tempo de vida teórico das fêmeas é de 21 anos e dos machos 11 anos (WEIS, 1980). GURGEL (1979) e NARAHARA $\boldsymbol{e} t$ al. (1985a) estabeleceram relações teóricas entre o comprimento e o peso corporais. Inicialmente elaboradas para espécies consideradas distintas, pode-se ver na figura 1 que as equações de GURGEL (1979) e NARAHARA et al. (1985a) e os dados de WEIS (1980), relacionando peso e comprimento corporais, são muito semelhantes.

Observações indicam que o crescimento de alevinos é rápido, já que atingem aproximadamente $5 \mathrm{~cm}$ de comprimento padrão com 30 dias de idade em sistemas artificiais. $\mathrm{O}$ crescimento de alevinos foi significativamente maior em exemplares expostos à escuridão que nos expostos continuamente à luz ou ao fotoperíodo normal. Os exemplares submetidos continuamente à luz ou ao fotoperíodo normal apresentaram nadadeiras danificadas, provavelmente devido a lutas entre eles (PIAIA $\boldsymbol{e t}$ al., 1999). O mesmo foi observado por PIAIA (1996) em larvas dessa espécie. Espécies submetidas a crescimento em escuridão contínua não tem qualquer tipo de dano nas nadadeiras (PIAIA et al., 1999). Uma vez que o estresse social pode diminuir a ingestão de alimento, através da redução do apetite (VOLPATO \& FERNANDES, 1994), provavelmente o melhor desempenho de crescimento de alevinos de $\boldsymbol{R}$. Quelen, obtido no escuro, é devido à

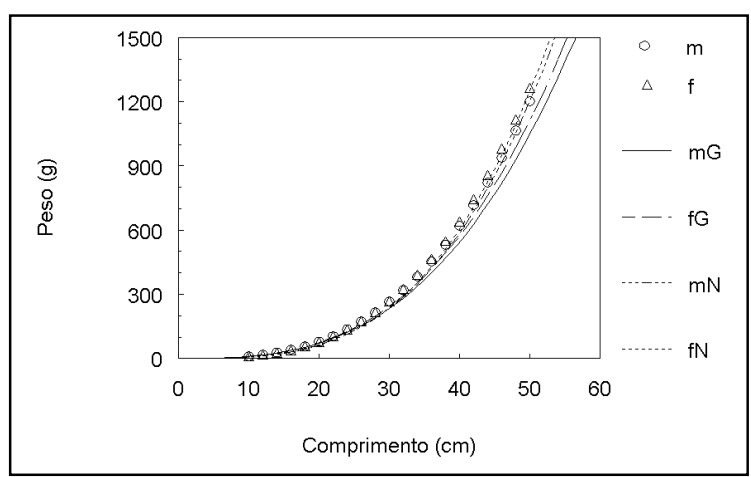

Figura 1 - Relação entre peso $(\mathrm{P})$ e comprimento $(\mathrm{C})$ corporais de Rhamdia quelen. Gráfico elaborado a partir de dados de WEIS (1980) (machos - m; fêmeas - f) e das equações abaixo:

$\begin{array}{lcc} & \text { GURGEL }(1979) & \text { NARAHARA } \text { et al. }(1985) \\ \text { Fêmeas } & \mathrm{P}=0,0100 \mathrm{C}^{2.97}(\mathrm{fG}) & \mathrm{P}=0,0037 \mathrm{C}^{3.25}(\mathrm{fN}) \\ \text { Machos } & \mathrm{P}=0,0106 \mathrm{C}^{2.94}(\mathrm{mG}) & \mathrm{P}=0,0043 \mathrm{C}^{3.20}(\mathrm{mN})\end{array}$

diminuição das lutas, e pelo fato de os alevinos ingerirem mais alimento no escuro. $\mathrm{O}$ menor coeficiente de variação de comprimento observado em alevinos mantidos na escuridão também indica que os níveis de interações sociais podem ser reduzidos nesse tratamento (PIAIA et al., 1999).

\section{HÁBITO ALIMENTAR E NUTRIÇÃO}

Adultos de $\boldsymbol{R}$. quelen são omnívoros, com uma clara preferência por peixes, crustáceos, insetos, restos vegetais, e detritos orgânicos (figura 2) (GUEDES, 1980; MEURER \& ZANIBONI FILHO, 1997). Essa espécie movimenta-se à noite e sai de seus esconderijos depois das chuvas para se nutrir dos escombros deixados ao longo dos rios. Os organismos encontrados no conteúdo gastrintestinal de $\boldsymbol{R}$. quelen não são restritos ao habitat bentônico, indicando que essa espécie é generalista com relação à escolha de alimento (GUEDES, 1980).

Em tanques externos de terra, LUCHINI \& SALAS (1983) sugerem uma densidade de estocagem de 10 larvas $/ \mathrm{m}^{2}$, utilizando zooplâncton como alimentação. Os mesmos autores utilizaram zooplâncton e ração para aves, mas a sobrevivência foi baixa (10-30\%), pois o alimento artificial não era adequado. Testes feitos em aquários de 200 $\ell$, com fluxo de água contínuo, utilizando: 1 - náuplios de Artemia salina; 2 - ração à base de farinhas de peixe, carne, milho e soja; 3 - zooplâncton; 4 - mistura de gema de ovo cozida, fígado cru e sangue coagulado, demonstraram que o melhor crescimento foi obtido com a utilização de zooplâncton, seguido da mistura do tratamento 4 (LUCHINI \& SALAS, 1985).

O regime de fígado bovino cru e pó de levedura Saccharomyces cerevisae apresenta-se como o único tratamento viável para ser usado na alimentação durante a primeira fase larval de $\boldsymbol{R}$. quelen (PIAIA \& RADÜNZ NETO, 1997a). PIAIA \& RADÜNZ NETO (1997b) testaram níveis crescentes de incorporação de levedura de álcool em substituição ao fígado bovino cru, obtendo dietas com níveis decrescentes de proteína bruta. Os índices de sobrevivência mais elevados foram com os tratamentos entre 60 a $80 \%$ de levedura. O nível de proteína na ração influenciou o comprimento total das larvas e a sobrevivência diminuiu $1,006 \%$ a cada $1 \%$ a mais de proteína na ração. Segundo os mesmos autores, dentro dos limites de proteína bruta estudados, há um efeito positivo de níveis mais elevados de proteína bruta sobre os comprimentos total e padrão e peso individual, porém há um efeito negativo sobre a sobrevivência das larvas de $\boldsymbol{R}$. quelen. A relação peso x sobrevivência aumentou 4,037 para cada $1 \%$ 


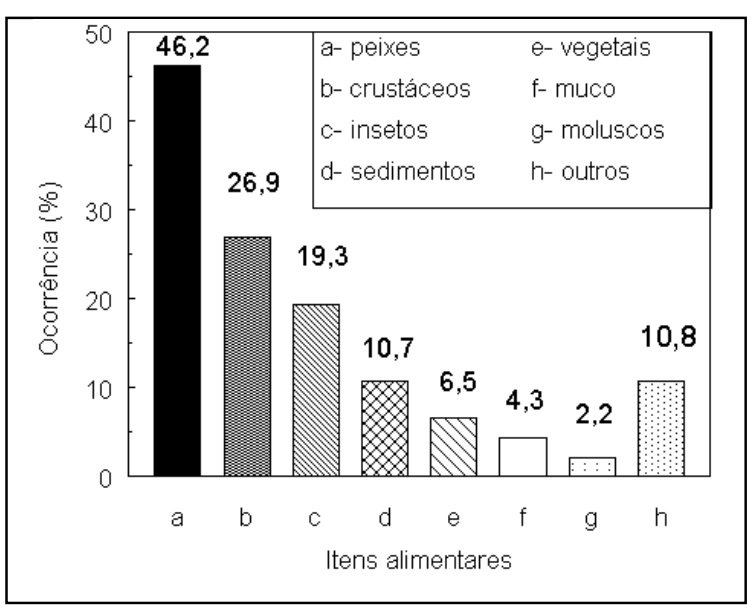

Figura 2 - Itens alimentares encontrados no estômago de Rhamdia quelen (adaptado de MEURER \& ZANIBONI FILHO, 1997).

de proteína na ração até o nível de $37,66 \%$ de proteína bruta.

ULIANA (1997) testou a influência de diferentes fontes de lipídeos em larvas de $\boldsymbol{R}$. quelen: óleo de colza, óleo de girassol, óleo de soja, óleo de fígado de bacalhau ou óleo de milho, adicionados a uma mesma base protéica. O mesmo autor testou também diferentes níveis de incorporação de óleo de colza, óleo e lecitina de soja e diferentes proporções de lecitina de soja, concluindo que esta é o mais eficiente suplemento lipídico para larvas de $\boldsymbol{R}$. que len.

\section{REPRODUÇÃO E DESENVOLVIMENTO EMBRIONÁRIO}

A maturidade sexual é atingida por volta de um ano de idade nos dois sexos. Os machos iniciam o processo de maturação gonadal com $13,4 \mathrm{~cm}$ e as fêmeas com $16,5 \mathrm{~cm}$. A partir de $16,5 \mathrm{~cm}$ e $17,5 \mathrm{~cm}$, todos os exemplares machos e fêmeas, respectivamente, estão potencialmente aptos para reprodução (NARAHARA et $\boldsymbol{a l}$., 1985b). Machos prontos para a espermiação liberam com facilidade o líquido espermático quando o abdome é pressionado. Além disso, o orifício genital é protraído (figura 3a). Fêmeas maduras apresentam o orifício genital hepirênico avermelhado e com dilatação ventral (MARDINI $\boldsymbol{e t}$ al., 1981) (figura 3b).

O período reprodutivo e os picos de desenvolvimento gonadal de $\boldsymbol{R}$. quelen podem variar a cada ano e de um lugar para outro. Em exemplares da região de Santa Maria - RS, o período reprodutivo se estende de agosto a fevereiro, e os picos de desenvolvimento gonadal ocorrem nos meses de agosto-setembro e janeiro-fevereiro (BOSSEMEYER, 1976). Contudo, MARDINI et al. (1981) encontraram reprodutores em adiantado estágio gonadal de setembro a maio, na Lagoa dos Quadros (RS); PAULA-SOUZA (1978) detectou maiores índices gonadossomáticos entre setembro e março em exemplares do Paraná. GURGEL (1979) destaca que o fator de condição para essa espécie é mais elevado no período de maturação gonadal. As células basófilas da pars distalis proximal (adenohipófise), que produzem as gonadotrofinas, apresentam uma correlação positiva com o índice gonadossomático, sendo que ocorre um aumento do peso da hipófise durante a maturação (CUSSAC \& MAGGESE, 1987).

O comportamento reprodutivo de $\boldsymbol{R}$. quelen assemelha-se ao de muitas espécies de água doce (MARDINI et al., 1981). Essa espécie é ovulípara no habitat natural e, quando prontos para desova, grandes cardumes procuram lugares de água rasa, limpa, pouco corrente e com fundo pedregoso. Os ovos são demersais e não aderentes. Há um bom sincronismo entre machos e fêmeas na hora da de-

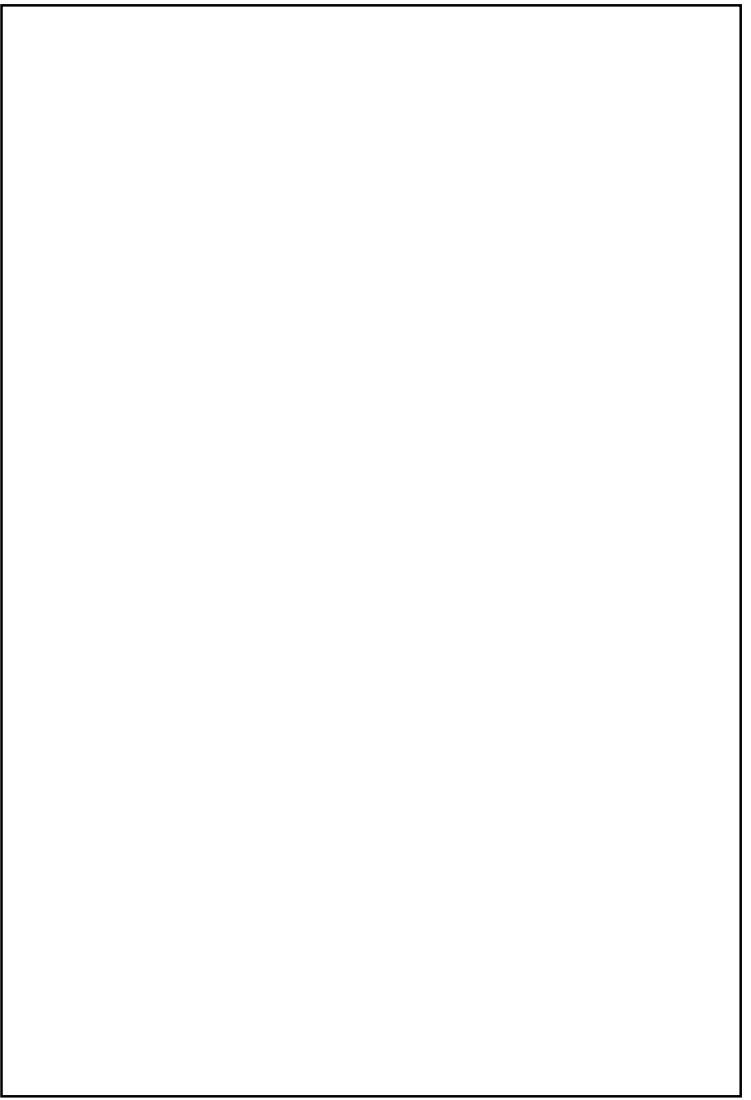

Figura 3 - Orifício urogenital de macho (A) e fêmea (B) de Rhamdia quelen prontos para espermiação e desova.

Ciência Rural, v. 30, n. 1, 2000. 
sova, que ocorre logo ao amanhecer (GODINHO $\boldsymbol{e t}$ al., 1978; ANDREATTA, 1979). A espécie não possui cuidado parental.

A desova dessa espécie é assincrônica, uma vez que os ovos são recrutados de populações heterogêneas de oócitos em desenvolvimento e são liberados em várias ocasiões do período reprodutivo. A fecundidade é baixa e apresenta relação com o comprimento total, peso total e peso da gônada (NARAHARA et al., 1989). PAULA-SOUZA (1978) descreveu 4 fases de desenvolvimento dos oócitos, mas de acordo com BOSSEMEYER (1976) e CUSSAC \& MAGGESE (1986), o período reprodutivo de fêmeas adultas possui 5 estágios de desenvolvimento de oócitos. O desenvolvimento dos oócitos de R. quelen é semelhante ao descrito por TYLER \& SUMPTER (1996) para teleósteos, de um modo geral.

ANDREATTA (1979) obteve, em sistema artificial, uma taxa de fertilização e eclosão dos ovos em torno de $95 \%$ e $90 \%$, respectivamente. Segundo MARDINI et al. (1981), é recomendável que a captura dos reprodutores para indução da desova seja feita após ocorrerem chuvas associadas a um aumento sensível de temperatura ambiente. Esses dois fatores, bem como um aumento dos níveis dos rios ou lagos, onde os exemplares se encontram, são considerados estímulos importantes para desencadear o final do processo de maturação e desova (PAULA-SOUZA, 1978).

As fêmeas de $\boldsymbol{R}$. quelen respondem bem à gonadotrofina coriônica humana (HCG), pois doses de 100-400U.I./kg são suficientes para provocar a desova (RADÜNZ NETO, 1981). Conforme a temperatura da água, varia o tempo de eclosão dos ovos. $\mathrm{Na}$ temperatura de $16^{\circ} \mathrm{C}$, a eclosão ocorre em torno de 3 dias, e com $24^{\circ} \mathrm{C}$ a eclosão demora em torno de 24h. Cada quilo de peso vivo de fêmea corresponde a, aproximadamente, 216.000 óvulos e cada $\mathrm{cm}^{3}$ apresenta 40 ovos hidratados de $\boldsymbol{R}$. quelen (MARDINI et al., 1981). A fertilização dos óvulos pode ser efetuada na água em que os reprodutores se encontram, mas MAGGESE et al. (1984) verificaram que os espermatozóides permanecem viáveis por uma hora em solução de Holtfreter (em mM): $60,34 \mathrm{NaCl} ; 2,70 \mathrm{KCl} ; 0,91 \mathrm{CaCl}_{2} ; 0,24 \mathrm{NaHCO}_{3}$, de modo que o recomendam como diluente para inseminação artificial. Espermatozóides em soluções de Holtfreter mais concentradas não iniciaram a motilidade, e alterações na concentração de $\mathrm{K}^{+}$não modificaram a motilidade espermática (CUSSAC \& MAGGESE, 1988a). Fotorreativação dos espermatozóides com luz ultravioleta só apresenta bons resultados em altas doses $\left(74-187 \times 10^{3}\right.$ erg. $\mathrm{min}^{-1} . \mathrm{mm}^{-}$ $\left.{ }^{2}\right)$. Baixas doses reduzem a sobrevivência dos embriões (VALCARCEL $\boldsymbol{e t}$ al., 1994).
O oócito recém desovado apresenta cor amarela clara e diâmetro de 1,0-1,3mm. Os ovos em desenvolvimento são esféricos e transparentes, apresentando uma camada gelatinosa envolvente. Após a fertilização, o diâmetro médio é de $2,8 \mathrm{~mm}$, com a camada gelatinosa, observando-se no pólo animal a formação de blastodisco sobre o periblasto e sob estes o vitelo, sendo todo esse conjunto envolvido por um pequeno espaço perivitelínico e por um córion nítido. Depois de intensa proliferação das células, o blastodisco expande-se sobre a superfície do vitelo e esse processo de migração celular forma o anel germinativo que envolve completamente o vitelo. Nota-se, então, uma segmentação somática e início da diferenciação da cabeça e da cauda e, em seguida, diferenciam-se as vesículas ópticas. A seguir, iniciam-se os batimentos cardíacos, e o cérebro aparece diferenciado. Em alguns embriões, a boca se encontra aberta, e há um fluxo de água através da primeira abertura branquial. Com $24 \mathrm{~h}$, a larva apresenta movimentos mandibulares e operculares, com diminuição do saco vitelínico. No quarto dia após a eclosão, o saco vitelínico é totalmente absorvido. No quinto dia, observam-se barbilhões bem desenvolvidos, dentículos nas maxilas, olhos pigmentados, nadadeiras peitorais e caudais formadas (GODINHO $\boldsymbol{e t}$ al. 1978). A morfogênese está quase completa após 4 meses (CUSSAC \& MAGGESE, 1988b). O desenvolvimento embrionário e larval é influenciado por fatores ambientais como temperatura e turbulência da água (GODINHO et al., 1978).

\section{PATOLOGIA}

SHAMA (1997) identificou várias bactérias patogênicas em lesões externas e rim de exemplares de $\boldsymbol{R}$. quelen no Rio Grande do Sul: Aeromonas hydrophila (patogênica facultativa, provoca graves infecções), Yersinia ruckeri ("doença da boca vermelha"), Plesiomonas shigelloides (seu surto ocorre em peixes submetidos ao estresse e à elevação da temperatura), Flavobacterium $\boldsymbol{s p}$ (doença branquial bacteriana), Pseudomonas $s p$ (patogênicas oportunistas), Vibrio $\boldsymbol{s p}$ (peste vermelha ou doença do furúnculo), Pasteurella sp (enfermidades e septicemia), Staphylococcus sp (úlceras no corpo), Micrococcus sp (lesões no dorso), Edwardsiella tarda (lesões na pele e desenvolvimento de abcessos), Actinobacter $s p$ (destruição dos ovos e causadora de infecções).

BRANDÃO (1977) encontrou, no intestino de $\boldsymbol{R}$. Quelen, Acanthostomum gnerii $e$ Fellodistomum $\boldsymbol{s p}$ (trematódeos digenéticos), no estômago, Genarchella genarchella e Genarchella 
dubia (parasitas), e nas brânquias e nadadeiras Clinostomum marginatum (na forma de metacercária).

\section{CONCLUSÕES}

Para um melhor aproveitamento desta espécie na piscicultura, são necessários mais estudos sobre alimentação artificial (principalmente com relação às necessidades vitamínicas), parâmetros físico-químicos da água adequados para crescimento e reprodução e sobre crescimento em cativeiro (densidade de estocagem e conversão alimentar). A área de melhoramento genético também é um campo inexplorado, com relação a esta espécie.

\section{REFERÊNCIAS BIBLIOGRÁFICAS}

ANDREATTA, E.R. Influência de diferentes dosagens e intervalos entre aplicações de gonodotropinas coriônica humana (HCG) sobre a reprodução do jundiá Rhamdia sapo (Valenciennes 1840). Santa Maria - RS, 1979. 51 p. Dissertação (Mestrado em Zootecnia) - Curso de Pósgraduação em Zootecnia, Universidade Federal de Santa Maria, 1979.

BRANDÃO, D.A. Trematódeos digenéticos de Rhamdia sapo (Valencienes, 1840) (jundiá) no estuário do Guaíba, Rio Grande do Sul, Brasil. Porto Alegre - RS, 197732 p. Dissertação (Mestrado em Medicina Veterinária) - Curso de Pósgraduação em Medicina Veterinária, Universidade Federal do Rio Grande do Sul, 1977.

BOSSEMEYER, I.M.K. Mudanças morfológicas no ovário de Rhamdia sapo (Pimelodidae) relacionadas com o ciclo reprodutivo. Santa Maria - RS, 1976. 48 p. Dissertação (Mestrado em Zootecnia) - Curso de Pós-graduação em Zootecnia, Universidade Federal de Santa Maria, 1976.

CHIPPARI-GOMES, A.R. Temperaturas letais de larvas e alevinos de jundiá, Rhamdia quelen (QUOY \& GAIMARD, 1824 - PISCES, PIMELODIDAE). Santa Maria - RS, 1998 70 p. Dissertação (Mestrado em Zootecnia) - Curso de Pósgraduação em Zootecnia, Universidade Federal de Santa Maria, 1998

CUSSAC, V.E., MAGGESE, M.C. Oogenesis in Rhamdia sapo (Pisces, Pimelodidae). Stages of the oocyte, eggs envelopes and effects of the human chorionic gonadotropin, Revista Brasileira de Biologia, v. 46, n. 1, p. 139-147, 1986.

CUSSAC, V.E., MAGGESE, M.C. Seasonal changes in the presumptive gonadotrophic cells of the catfish Rhamdia sapo (Pisces, Pimelodidae) in relation to gonadosomatic index. Comunicaciones Biologicas, v. 6, n. 2, p. 113-123, 1987.

CUSSAC, V.E., MAGGESE, M.C. Effects of salt solutions on the fertilizing ability and activation of gametes in the catfish, Rhamdia sapo, (Pisces, Pimelodidae). Revista Brasileira de Biologia, v. 48, n. 2, p. 203-211, 1988a.

CUSSAC, V.E., MAGGESE, M.C. Ontogeny the maxillary barbels and palatine-maxillary mechanism in the catfish Rhamdia sapo (Pisces, Pimelodidae). Revista Brasileira de Biologia, v. 48, n. 2, p. 195-201, 1988b.
GODINHO, H.M., BASILE-MARTINS, M.A., FENERICH, N. et al. Desenvolvimento embrionário e larval de Rhamdia hilarii (Valenciennes, 1840) (Siluriformes, Pimelodidae). Revista Brasileira de Biologia, v. 38, n. 1, p. 151-156, 1978.

GUEDES, D.S. Contribuição ao estudo da sistemática e alimentação de jundiás (Rhamdia spp) na região central do Rio Grande do Sul (Pisces, Pimelodidae). Santa Maria - RS, 1980. 99p. Dissertação (Mestrado em Zootecnia) - Curso de Pós-graduação em Zootecnia, Universidade Federal de Santa Maria, 1980

GURGEL, H.C.B. Aspectos do comportamento biológico de Rhamdia branneri Haseman, 1911, (Osteichthyes, Siluriformes, Pimelodidae). Curitiba - PR, 1979. 53 p. Dissertação (Mestrado em Zoologia), Curso de Pós-graduação em Zoologia, Universidade Federal do Paraná, 1979.

LOPES, J.M. Influência do pH da água na sobrevivência e crescimento de larvas de jundiá Rhamdia quelen ( QUOY \& GAIMARD, 1824, PISCES, PIMELODIDAE) em duas épocas de desovas. Santa Maria - RS, 1998.60 p. Dissertação (Mestrado em Zootecnia), Curso de Pós-graduação em Zootecnia, Universidade Federal de Santa Maria, 1998.

LUCHINI, R., SALAS, T. Cria de larvas de Rhamdia sapo (Val.) Eig. en estanques primeros ensayos. Revista de la Associacion de Ciencias Naturales del Litoral, v. 14, n. 1, p. 79-86, 1983

LUCHINI, L., SALAS, T.A. Primer alevinaje de bagre sudamericano, Rhamdia sapo (Val.) Eig. en condiciones controladas. Revista de la Associacion de Ciencias Naturales del Litoral, v. 16, n. 2, p. 137-147, 1985

MAGGESE, M.C., CUKIER, M., CUSSAC, V.E. Morphological changes, fertilizing ability and motility of Rhamdia sapo (Pisces, Pimelodidae) sperm induced by media of different salinities. Revista Brasileira de Biologia, v. 44, n. 4, p. 541$546,1984$.

MARCHIORO, M.I. Sobrevivência de alevinos de jundiá (Rhamdia quelen Quoy \& Gaimard, 1824, Pisces, Pimelodidae) à variação de $\mathrm{pH}$ e salinidade da água de cultivo. Santa Maria, RS, 1997. 87p. Dissertação (Mestrado em Zootecnia) - Curso de Pós-graduação em Zootecnia, Universidade Federal de Santa Maria, 1997.

MARDINI, C.V., SILVEIRA, M.A., BARENHO D.H.L. Técnica de indução da desova em jundiá (Rhamdia quelen) empregada na estação experimental de piscicultura da Lagoa dos Quadros. Porto Alegre: Secretaria da Agricultura,1981. 14 p.Documento ocasional n.4.

MEURER, S., ZANIBONI FILHO, E. Hábito alimentar do jundiá Rhamdia quelen (Pisces, Siluriformes, Pimelodidae), na região do alto rio Uruguai. In: XII ENCONTRO BRASILEIRO DE ICTIOLOGIA, São Paulo, SP, 1997. Anais... São Paulo: SBI, 1997. 420 p. p. 29.

NARAHARA, M.Y., GODINHO, H.M., FENERICH-VERANI, N., et al. Relação peso-comprimento e fator de condição de Rhamdia hilarii (Valenciennes, 1840) (Osteichthyes, Siluriformes, Pimelodidae). Boletim do Instituto de Pesca, v. 12, n. 4, p. 13-22, 1985a.

NARAHARA, M.Y, GODINHO, H.M., ROMAGOSA, E. Estrutura da população de Rhamdia hilarii (Valenciennes, 1840) (Osteichthyes, Siluriformes, Pimelodidae). Boletim do Instituto de Pesca, v. 12, n. 3, p. 123-137, 1985b. 
NARAHARA, M.Y., GODINHO, H.M, ROMAGOSA, E. Tipo de desova e fecundidade do bagre, Rhamdia hilari (Valenciennes, 1840) (Siluriformes, Pimelodidae). Boletim do Instituto de Pesca, v. 16, n. 1, p. 37-45, 1989.

PAULA-SOUZA, G. Reprodução de Rhamdia branneri, 1911 (Pisces, Siluriformes) e suas relações com fatores abióticos. Curitiba - PR, 1978. 66 p. Dissertação (Mestrado em Zoologia) - Curso de Pós-graduação em Zoologia, Universidade Federal do Paraná, 1978.

PIAIA, R. Efeito do uso de diferentes fontes protéicas e diferentes níveis de proteína sobre o crescimento e sobrevivência de larvas do jundiá Rhamdia quelen. Santa Maria - RS, 1996. 47 p. Dissertação (Mestrado em Zootecnia) - Curso de Pós-graduação em Zootecnia, Universidade Federal de Santa Maria, 1996

PIAIA, R., RADÜNZ NETO, J. Avaliação de diferentes fontes protéicas sobre o desempenho inicial de larvas do jundiá Rhamdia quelen. Ciência Rural, Santa Maria, v. 27, n. 2, p. 319-323, 1997a.

PIAIA, R., RADUNZ NETO, J. Efeito de níveis crescentes de levedura de álcool em rações contendo fígado bovino sobre a performance de larvas de jundiá Rhamdia quelen. Ciência Rural, Santa Maria, v. 27, n. 2, p. 313-317, 1997 b.

PIAIA, R., TOWNSEND, C.R., BALDISSEROTTO, B., Growth and survival of fingerlings of Rhamdia quelen exposed to different light regimes. Aquaculture International v. 7, p. 201-205, 1999.

RADÜNZ NETO, J. Desenvolvimento de técnicas de reprodução e manejo de larvas e alevinos de jundiá (Rhamdia quelen). Santa Maria - RS 1981. 77 p. Dissertação (Mestrado em Zootecnia) - Curso de Pós-graduação em Zootecnia, Universidade Federal de Santa Maria, 1981.

SHAMA, S. Identificação de bactérias patogênicas em cultivo semi-intensivo de Jundiá (Rhamdia quelen), Pisces, Pimelodidae. Santa Maria - RS, 1997. 57p. Dissertação (Mestrado em Zootecnia) - Curso de Pós-graduação em
Zootecnia,, Universidade Federal de Santa Maria, 1997.

SILFVERGRIP, A.M.C. A sistematic revision of the neotropical catfish genus Rhamdia (Teleostei, Pimelodidae). Stockholm, Sweden, 1996. 156p. (PhD Thesis) - Department of Zoology, Stockholm University and Department of Vertebrate Zoology, Swedish Museum of Natural History, 1996.

TYLER, C.R., SUMPTER, J.P. Oocyte growth and development in teleosts. Reviews in Fish Biology and Fisheries, v. 6, p. 287-318, 1996.

TOWNSEND, C.R., PIAIA, R., BALDISSEROTTO, B. Tolerância de alevinos de Rhamdia quelen (jundiá) a variações de $\mathrm{pH}$ e de dureza da água utilizada no cultivo. In: XXVI ENCONTRO ANUAL DE CIÊNCIAS FISIOLÓGICAS, Porto Alegre, 1997. Anais... Porto Alegre: SFRES, 1997. 88p. p. 65.

ULIANA, O. Influência de diferentes fontes e níveis de lipídeos sobre a criação de larvas de jundiá (Rhamdia quelen), Pisces, Pimelodidae. Santa Maria - RS, 1997. 57 p. Dissertação (Mestrado em Zootecnia) - Curso de Pósgraduação em Zootecnia, Universidade Federal de Santa Maria, 1997.

VALCARCEL, A., GUERRERO, G., MAGGESE, M.C. Hertwing effect caused by UV-irradiation of sperm of the catfish, Rhamdia sapo (Pisces, Pimelodidae), and its photoreactivation. Aquaculture, v. 128, p. 21-28, 1994.

VOLPATO, G.L., FERNANDES, M.O. Social control of growth in fish. Brazilian Journal of Medical and Biological Research, v. 27 p. 797-810, 1994.

WEIS, M.L.C. Interpretação da idade e cálculo da curva de crescimento do jundiá, Rhamdia quelen (QUOY \& GAIMARD, 1824) do banhado de Santa Catarina - RS. Santa Maria - RS, 1980. 93 p. Dissertação (Mestrado em Zootecnia) - Curso de Pós-graduação em Zootecnia, Universidade Federal de Santa Maria, 1980.

Ciência Rural, v. 30, n. 1, 2000. 